ORIGINAL ARTICLE-

Volume 15 Issue 22020

DOI: $10.21315 /$ aos2020.15.2.455

ARTICLE INFO

Submitted: 02/05/2020

Accepted: $17 / 11 / 2020$

Online: 24/12/2020

\section{The Efficacy of Two Different Concentrations of Local Anaesthetic on Pain in Mandibular Third Molar Surgery}

\author{
Thippayarat Piernon ${ }^{\mathrm{a}}$, Basel Mahardawi ${ }^{\mathrm{a}}$, Kumar KC ${ }^{\mathrm{a}}$, Chakorn \\ Vorakulpipat ${ }^{a}$, Bishwa Prakash Bhattarai ${ }^{\mathrm{b}}$, Natthamet Wongsirichat ${ }^{\mathrm{b} *}$
${ }^{a}$ Department of Oral Maxillofacial Surgery, Faculty of Dentistry, Mahidol University, 6 Yothi Street, Rachathewee District, Bangkok \\ 10400, Thailand \\ ${ }^{b}$ Walailak University International College of Dentistry, 979/42-46 \\ Phahonyothin Road, 19th Floor SM Tower, Phaya Thai District, \\ Bangkok 10400, Thailand
}

${ }^{\star}$ Corresponding author: natthamet.won@mahidol.ac.th

To cite this article: Piernon T, Mahardawi B, Kumar KC, Vorakulpipat C, Bhattarai BP, Wongsirichat N (2020). The efficacy of two different concentrations of local anaesthetic on pain in mandibular third molar surgery. Arch Orofac Sci, 15(2): 159-173. https://doi.org/10.21315/ aos2020.15.2.455

To link to this article: https://doi.org/10.21315/aos2020.15.2.455

\begin{abstract}
Mepivacaine is a common local anaesthetic used with claims of a high safety profile. There are two commercial types, $2 \%$ mepivacaine with vasoconstrictor and $3 \%$ without vasoconstrictor. There are many suggestions regarding the usage of plain 3\% without vasoconstrictor for systemic medical problems, however, there have not been any previous studies to confirm this necessity in impacted lower third molar surgery (ILTMS). This study aims to evaluate the anaesthetic efficiency and the effect on the patient of $2 \%$ and $3 \%$ mepivacaine, adding vasoconstrictor to the 3\% mepivacaine. This crossover study comprised of 24 patients with bilateral, symmetrically positioned, impacted lower third molars. Patients received either $2 \%$ or $3 \%$ mepivacaine for the inferior alveolar nerve block (IANB). Onset and duration of anaesthesia, and haemodynamic considerations were analysed as primary outcomes. Furthermore, pain, duration of postoperative anaesthesia and pulp vitality were analysed as secondary outcomes. Different concentrations of mepivacaine showed similar anaesthetic onset time $(p>0.05)$. There was no statistically significant difference regarding the duration of anaesthesia, as well as the postoperative analgesia $(p>0.05)$. The two concentrations did not lead to any haemodynamic changes or complications during ILTMS. Thus, adding the vasoconstrictor to mepivacaine 3\% did not cause any adverse effects on the patients intra or postoperatively. Therefore, it is possible for dentists to use only $2 \%$ mepivacaine with vasoconstrictor for IANB effectively and safely when the case necessitates the need for a vasoconstrictor, or in other words, longer duration of haemostasis.
\end{abstract}

Keywords: Anaesthetic efficiency; inferior alveolar nerve block; local anaesthesia; mepivacaine; third molar surgery 


\section{INTRODUCTION}

Pain is a common incidence that usually occurs throughout dental treatment, making patients feel uncomfortable. Thus, pain control is an important key in an attempt to reduce the patient's fear and anxiety which is related to dental procedures (Katyal, 2010; Su et al., 2014). Pain management plays an essential role in dealing with patients who undergo dental interventions. Out of these points comes the role of local anaesthetics, which are widely used for pain and discomfort control in dental procedures (Su et al., 2014; Senes et al., 2015).

Several local anaesthetics are available to use by dental clinicians. These agents can produce a rapid onset of anaesthetic effects and adequate duration of anaesthesia (Hawkins and Moore, 2002; Colombini et al., 2006). However, previous studies still do not provide enough reports on the systemic toxicity and neurotoxicity caused by local anaesthetics (Hawkins and Moore, 2002; Adeleye et al., 2020; Arumugam et al., 2020).

All local anaesthetics that are currently available in dentistry have vasodilation properties, making them able to increase blood flow within the tissues at the injection site. This, in turn, may increase the intraoperative bleeding and affect surgical procedures leading to complications (Sisk, 1992). However, the addition of vasoconstrictors can help to reduce intraoperative bleeding, as well as decrease the risk of systemic toxicity. Regarding vasoconstrictors, epinephrine is the most widely used vasoconstrictor in dentistry (Sisk, 1992; Santos et al., 2007).

Mepivacaine is one of the amide-type dental local anaesthetics that is frequently administered in dental procedures (Colombini et al., 2006; Bortoluzzi et al., 2008; Su et al., 2014). Various previous studies reported that the anaesthetic efficacy of mepivacaine is similar to that in lidocaine (Giovannitti et al., 2013; Su et al., 2014). It has a slight vasoconstriction effect which differs from other amides, and this leads to a longer period of anaesthetic duration without the use of vasoconstrictors (Su et al., 2014). The plain $3 \%$ mepivacaine, or mepivacaine without vasoconstrictor, is an alternative dental local anaesthetic for patients whom vasoconstrictors would be contraindicated or might have an effect on their general health (Giovannitti et al., 2013).

Mepivacaine $\quad 2 \% \quad$ with $1: 100,000$ epinephrine, or $3 \%$ mepivacaine plain (without vasoconstrictor) are two types of local anaesthetics that are conventionally used in dental surgical interventions. The anaesthetic duration of 3\% plain mepivacaine is less, and it is mainly given in the case of operations that consume a relatively shorter period in clinical dentistry. However, during any routine dental procedure, especially for impacted lower third molar surgery (ILTMS), complications may arise, or difficulties may take place, which may lead to a prolonged procedure time. It may also cause massive bleeding in the case of a local anaesthetic without vasoconstrictor.

Higher volumes and concentrations of local anaesthetics may lead to systemic toxicity in patients. On the other hand, using vasoconstrictors, such as epinephrine slows the rate of absorption of local anaesthetics which prolongs anaesthetic duration, decreases the bleeding, and reduces the risk of systemic toxicity (Moodley, 2017). In addition, the effect of exogenous epinephrine in blood pressure is less than the endogenous epinephrine secreted in response to stress induced by the surgical procedure (Seto et al., 2016). Therefore, the addition of epinephrine to mepivacaine has improved the quality of local anaesthetic effect by increasing the effect and period of anaesthesia, providing better haemostasis, as well as reducing the systemic toxic impact (Son et al., 2016).

In dentistry, it is common to use $2 \%$ mepivacaine with 1:100,000 epinephrine as a local anaesthetic with vasoconstrictor. However to the best of the authors' knowledge, there are no previous studies concerning the 
anaesthetic efficiency of $3 \%$ mepivacaine with the addition of a vasoconstrictor, especially epinephrine. Thus, this research was conducted to investigate the anaesthetic efficiency and effects of $2 \%$ mepivacaine with $1: 100,000$ epinephrine and 3\% mepivacaine with 1:100,000 epinephrine (freshly prepared) in patients undergoing the surgical removal of symmetrically positioned impacted lower third molars. The findings of this research would help the clinicians to decide the type of mepivacaine (3\% with epinephrine versus $2 \%$ with epinephrine), should it be the anaesthesia of choice for third molar surgery.

\section{MATERIALS AND METHODS}

This prospective randomised controlled split-mouth clinical crossover study was performed at the Oral and Maxillofacial Surgery Clinic of the Faculty of Dentistry, Mahidol University, Thailand. The protocol of this study was approved by the Ethics Committee of the Institutional Review Board in Mahidol University (COA.No.MU-DT/ PY-IRB 2018/027.0705). All patients were informed about the purpose of this study and all the procedures that were going to be performed. Patients who approved to participate signed a consent form after receiving all the necessary instructions.

\section{Sample Size Calculation and Patient Selection}

This study lasted from May until September 2018. The sample size was calculated using $G^{\star}$ Power 3.1.0 software, taking $\alpha$ error $=0.05$, power $=95 \%$. To eliminate the effect of any possible drop out, an approximate $10 \%$ of the suggested number after calculating the sample size was added, therefore, the initial sample size was 35 patients. Ten patients withdrew from the second appointment and the total of the study group comprised of 25 patients. One patient developed paraesthesia after the first surgery, after using $2 \%$ mepivacaine with 1:100,000 epinephrine, and missed the second appointment. Data from this patient was discarded according to withdrawal criteria (Fig. 1). The reduction in sample size decreased the power of the test from $95 \%$ to $84 \%$.

A patient withdrawal from this study could take place if any of the following occurred:

1. Patient's lack of the protocol adherence;

2. Any incidence of adverse events which are unrelated to the local anaesthetic agents (e.g., paraesthesia);

3. Any sudden necessity to use different types or doses of the dental local anaesthesia on a patient; and

4. Patient decided to withdraw from participation.

Table 1 showed the data related to the sample. Twenty-four patients selected through a computer-generated random sampling completed this study including 9 males and 15 females. Their age ranged from 18 to 37 years old (mean age of 22 years). All patients had symmetrically impacted lower third molars. The symmetrical positions (almost same angulation and position of the bilateral third molars) were decided after the evaluation of panoramic radiographs. Table 2 showed the inclusion and exclusion criteria that were followed in this study. 


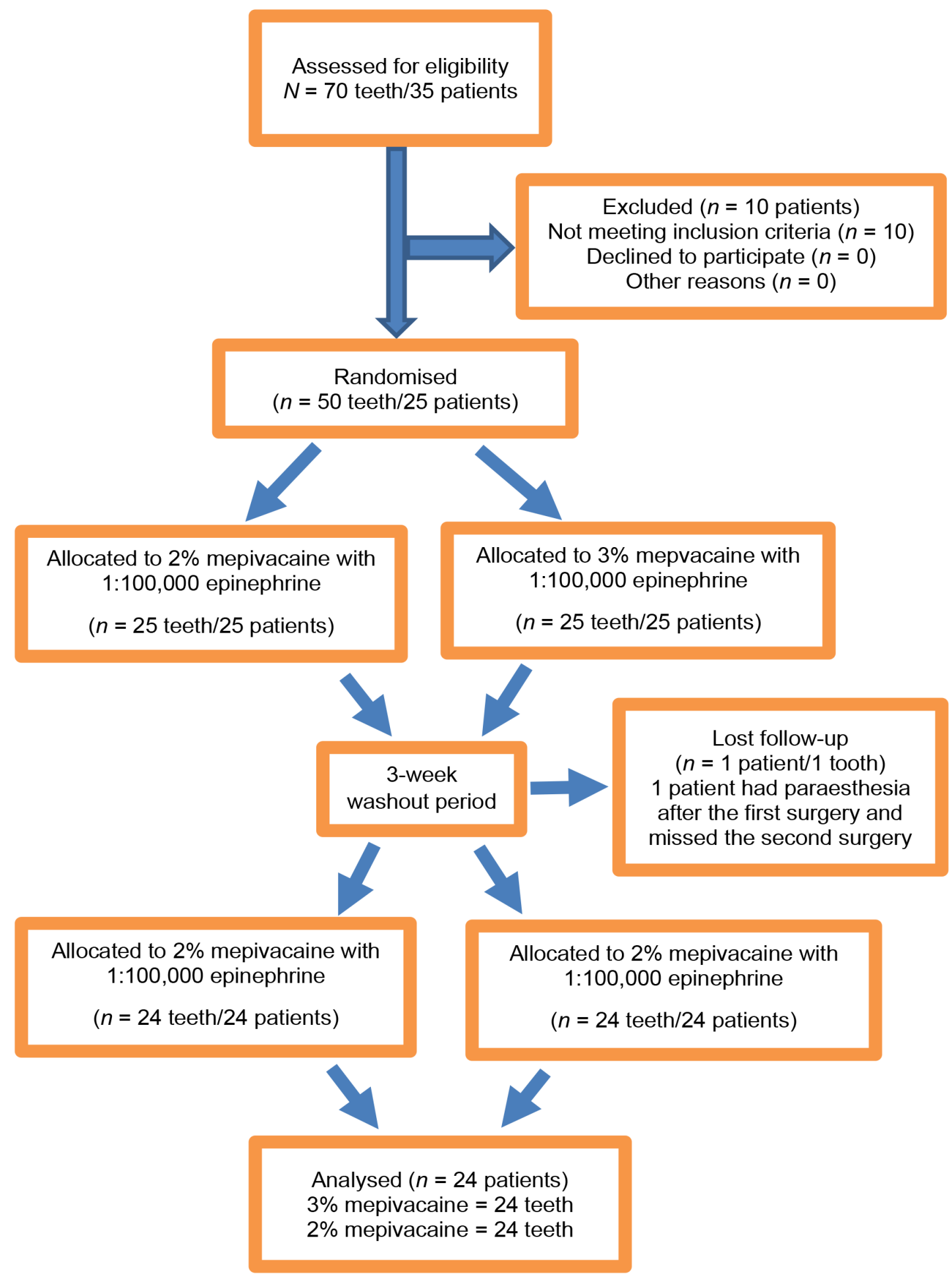

Fig. 1 Flow diagram for the selection criteria of this study. 
Table 1 Comparison of the parameters between 2\% mepivacaine with 1:100,000 epinephrine and 3\% mepivacaine with 1:100,000 epinephrine groups

\begin{tabular}{lcc}
\multirow{2}{*}{ Measurement } & \multicolumn{2}{c}{$\mathbf{1 : 1 0 0 , 0 0 0}$ epinephrine } \\
\cline { 2 - 3 } & $\mathbf{2 \%}$ mepivacaine & $\mathbf{3 \%}$ mepivacaine \\
\hline Mean age (years) & 22 & 22 \\
Age range (years) & 18 to 37 & 18 to 37 \\
Females, $n(\%)$ & $15[62.5]$ & $15[62.5]$ \\
Males, $n(\%)$ & $9[37.5]$ & $9[37.5]$ \\
\hline
\end{tabular}

Table 2 The eligibility and exclusion criteria selection of the patient in this research study

\begin{tabular}{|c|c|}
\hline Eligibility criteria selection & Exclusion criteria selection \\
\hline $\begin{array}{l}\text { 1. Bilateral impacted lower third molars that were } \\
\text { symmetrical on both sides, and required flap opening, } \\
\text { bone removal and tooth sectioning during the } \\
\text { intervention. }\end{array}$ & $\begin{array}{l}\text { 1. The patient has medical history of any systemic } \\
\text { disease. }\end{array}$ \\
\hline $\begin{array}{l}\text { 2. No signs or symptoms of infection or inflammation on } \\
\text { the lower third molar areas. }\end{array}$ & $\begin{array}{l}\text { 2. Allergy to the local anaesthetic agents or } \\
\text { nonsteroidal anti-inflammatory drugs. }\end{array}$ \\
\hline $\begin{array}{l}\text { 3. Healthy patients (ASA I), with the absence of any } \\
\text { systemic condition. (Wolters et al., 1996) }\end{array}$ & 3. Pregnancy or current lactation patient. \\
\hline $\begin{array}{l}\text { 4. The patient is not taking any medication, which would } \\
\text { affect the pain perception. }\end{array}$ & $\begin{array}{l}\text { 4. The patient with facial deformities which might } \\
\text { intervene local anaesthetic administration, surgery, } \\
\text { or future investigations. }\end{array}$ \\
\hline $\begin{array}{l}\text { 5. The patient is able to understand and fulfil the } \\
\text { investigator's instructions. }\end{array}$ & $\begin{array}{l}\text { 5. The presence of infection or inflammation on the } \\
\text { lower third molar sites. }\end{array}$ \\
\hline & 6. Any drug intake. \\
\hline & $\begin{array}{l}\text { 7. Inability to adhere to the postoperative instructions, } \\
\text { or attend all follow-up visits during the study period. }\end{array}$ \\
\hline
\end{tabular}

Note: ASA - American Society of Anesthesiologists.

\section{Research Conduction}

Each patient was assigned to receive two different concentrations of $2 \%$ mepivacaine with 1:100,000 epinephrine (Scandonest $2 \%$ Special, Septodont ${ }^{\mathbb{B}}$, France), and 3\% mepivacaine with 1:100,000 epinephrine. Each cartridge had $18 \mu \mathrm{g}$ of epinephrine, and one of these solutions was used for each side. The local anaesthetic to be selected for the first surgery on one side was chosen by a coin toss (the other side was done using the other concentration), which was done by an assistant whose job was to assign the local anaesthetic without informing the surgeon or the person who will measure the rest of the data. All patients were appointed for two different surgical appointments, spaced three to four weeks in between as a washout period. The patient was operated with a different concentration of local anaesthesia at each appointment using the standard inferior alveolar nerve block (IANB), which involves the needle insertion in close proximity to the mandibular foramen in order to deliver the anaesthetic solution to the inferior alveolar nerve before it continues into the foramen (Khalil, 2014), as the method to achieve local anaesthesia. The local anaesthetic was injected by the same dentist in every case. Each patient had undergone the same standard surgical procedure on both sides of the mandible, and this procedure was performed by the same surgeon in all cases. Another dentist carried out the measurements and data evaluation 
of this research without having any previous information regarding the concentration of mepivacaine that was used in each case. At the time of data collection, the information concerning the local anaesthetic were outlined by the assistant who knew the type of local anaesthetic used. However, as mentioned before, his job was only to assign the correct type to each patient and this was revealed after the surgery, follow-up, and all data measurements were completed.

\section{Preparation of 1:100,000 Epinephrine 3\% Mepivacaine}

The preparation of dental local anaesthetic was done immediately before administration. About $3 \%$ of mepivacaine with 1:100,000 epinephrine was prepared by using a micropipette to withdraw $0.018 \mathrm{~mL}$ of epinephrine bitartrate and adding it into a $1.8 \mathrm{~mL}$ cartridge that contained $30 \mathrm{mg} / \mathrm{mL}$ of mepivacaine. Regarding the administration of the anaesthetic solution, either $2 \%$ mepivacaine with $1: 100,000$ epinephrine or 3\% mepivacaine with 1:100,000 epinephrine was drawn from the original container to the disposable syringe reaching an amount of $1.8 \mathrm{~mL}$. Moreover, the $\mathrm{pH}$ of each anaesthetic solution was tested by selecting 10 random samples of $2 \%$ mepivacaine with epinephrine and 3\% mepivacaine with 1:100,000 epinephrine. In addition, the $\mathrm{pH}$ of $3 \%$ plain mepivacaine was also tested. This procedure was performed using the digital $\mathrm{pH}$ meter. The $\mathrm{pH}$ tester was calibrated with a $\mathrm{pH}$ buffer solution before carrying out the test.

\section{Steps of the Surgical Procedure}

At the beginning of each appointment and before any local anaesthetic was administered, the electrical pulp test (EPT) was done by using the electric pulp tester device (Digitest ${ }^{\mathrm{TM}}$ II Pulp Vitality Tester, USA) to record the baseline vitality of the canine and lower first molar in the same quadrant of the lower third molar surgical site. Before starting the operation, each patient was informed about all the details to ensure the understanding of pain rating by using the visual analogue scale (VAS) on the $100-\mathrm{mm}$ line, which represents the degree of pain.

Initially, the intraoral antisepsis using $0.2 \%$ chlorhexidine gluconate was gained. Then the patients were administered with $1.8 \mathrm{~mL}$ of local anaesthetic for the IANB in order to achieve the anaesthesia of the lingual and inferior alveolar nerves. The patients were questioned about the numbness or tingling sensation in their lower lip and tongue on the same side of surgery every minute during the first $15 \mathrm{~min}$ of the administration. When the patient first detected any sense of pain, that information was recorded. If no lip and tongue numbness were achieved within $15 \mathrm{~min}$, a second injection of the same local anaesthetic was performed. One patient needed a second IANB when using $2 \%$ mepivacaine with a vasoconstrictor, and another patient needed a second IANB after the administration of 3\% mepivacaine with vasoconstrictor. If there was any case where the patient's lip and tongue were not numb within $15 \mathrm{~min}$ after the second administration, the IANB would have been considered unsuccessful and the patient would have been excluded from the current study, however, this was not reported in any case in our study. After the initial injection, the EPT was performed on the same teeth that were tested before local anaesthetic administration, and the EPT output scores were recorded.

When confirming adequate anaesthesia from the IANB, an additional $0.9 \mathrm{~mL}$ of the same mepivacaine was administered for the buccal nerve block to complete the local anaesthesia of the surgical site. Then surgery was carried out, and the patient's lower third molar was surgically removed. After three to four weeks washout period for each patient, he/she had undergone the same procedure for the impacted lower third molar on the opposite side, following the same standards.

At the time of each completed surgery, each patient was given the routine postoperative 
instructions and received a detailed explanation to be able to fill the patient record form accurately. Thus, it will be possible to investigate the local anaesthetic duration, in which the timespan is determined by the sensation of the lower lip returning to the normal state. The patients were also informed to report any adverse effects that occurred during postoperative period.

For postoperative pain control, all patients received $400 \mathrm{mg}$ ibuprofen (one tablet three times a day after a meal), and $500 \mathrm{mg}$ paracetamol (one tablet every six hours as necessary for pain) orally for five days. Each surgical procedure in this study required a soft tissue flap elevation and bone removal. Based on the guidelines of the centre where the study was conducted, $500 \mathrm{mg}$ amoxicillin (one capsule, four times a day, before a meal and before bed) or $300 \mathrm{mg}$ clindamycin (in case of the allergy to amoxicillin; one tablet, three times a day, after a meal) was prescribed for five days to prevent infection. Patients were instructed not to terminate the use of the antibiotic drug and take it as prescribed.

\section{Data Collection}

The data collection was explained in Table 3.

\section{Statistical Analysis and Evaluation}

Data analysis was done by using the SPSS software programme (SPSS Version 18.0 for Windows, Chicago, IL, USA). The Kolmogorov-Smirnov test was used to evaluate the normal distribution of the measurements. Paired $t$-test was used to analyse variables with normal distribution. The nonparametric measurements with abnormal distribution were analysed by Wilcoxon test. A $p$-value of $<0.05$ was set for the statistical significance level. For the $\mathrm{pH}$ comparison, one-way ANOVA was performed.
Table 3 The parameter of data collection in this research study

\begin{tabular}{|c|c|}
\hline Parameter & Unit of measurement \\
\hline $\begin{array}{l}\text { Type of lower third } \\
\text { molars impaction }\end{array}$ & $\begin{array}{l}\text { Pell \& Gregory classification } \\
\text { and Winter's classification }\end{array}$ \\
\hline $\mathrm{pH}$ of each anaesthetic & Number \\
\hline $\begin{array}{l}\text { Electrical pulp test (EPT) } \\
\text { before and after local } \\
\text { anaesthetic injection }\end{array}$ & Number (unit) \\
\hline $\begin{array}{l}\text { Total volume of local } \\
\text { anaesthetic }\end{array}$ & Quality (mL) \\
\hline $\begin{array}{l}\text { Subjective and objective } \\
\text { onset }\end{array}$ & Time (min) \\
\hline Anaesthesia duration & Time (min) \\
\hline $\begin{array}{l}\text { Duration of surgical } \\
\text { period }\end{array}$ & Time (min) \\
\hline $\begin{array}{l}\text { Duration of } \\
\text { postoperative } \\
\text { anaesthesia }\end{array}$ & Time (min) \\
\hline $\begin{array}{l}\text { Adverse reactions } \\
\text { during the operation } \\
\text { and during the } \\
\text { postoperative period }\end{array}$ & Descriptive explanation \\
\hline $\begin{array}{l}\text { Haemodynamic } \\
\text { measurements of } \\
\text { systolic, diastolic blood } \\
\text { pressure and heart rate } \\
\text { were done before the } \\
\text { surgery as baseline and } \\
\text { immediately after this } \\
\text { following procedure. }\end{array}$ & $\begin{array}{l}\text { All haemodynamic } \\
\text { measurements were } \\
\text { performed with an automatic } \\
\text { Sphygmomanometer device. } \\
\text { The first injection of the } \\
\text { dental local anaesthesia, the } \\
\text { soft tissue incision, the bone } \\
\text { removal, the tooth sectioning, } \\
\text { the tooth removal and the } \\
\text { completion of the suturing. }\end{array}$ \\
\hline $\begin{array}{l}\text { Subjective pain } \\
\text { evaluation while } \\
\text { injection and tooth } \\
\text { sectioning, with } \\
\text { administration of } \\
\text { the local anaesthesia } \\
\text { and while the tooth } \\
\text { sectioning. }\end{array}$ & $\begin{array}{l}\text { Visual analogue scale (VAS) } \\
\text { with the scores from } 0 \text { to } 100 . \\
0 \text { indicates "no pain" and } 100 \\
\text { indicates "worst pain". }\end{array}$ \\
\hline
\end{tabular}

\section{RESULTS}

This randomised control trial consisted of 25 patients as a start, however, one patient developed lip paraesthesia after the first surgery, therefore, he refused to proceed with the next step and was excluded from this study, resulting in 24 patients who 
finished all the procedures, with complete data and follow-up period. The age range was 18 to 37 , and all patients were healthy with no known medical history. Each patient had undergone third molar surgery after administering one of the two types of local anaesthetics used in this study. The surgical procedure on each side was carried out in separate appointments to prevent any kind of discomfort, which may affect the results, limiting the possibility of patients providing inaccurate reports regarding the pain on each side. Onset and duration of anaesthesia, as well as haemodynamic considerations and adverse effects were analysed as primary endpoints of this study. In addition, duration of postoperative anaesthesia and pulp vitality were recorded and analysed as secondary outcomes. Pain was also included in the secondary outcomes because this local anaesthetic is, of course, already tested and proven to be effective against pain. Adding the vasoconstrictor will not cause any change to this but will improve the efficiency of the mepivacaine.

\section{Positions of Impacted Lower Third Molars}

Table 4 showed the similarities in angulation and positions of impacted lower third molars from panoramic radiographs with no vertical position. The classification of third molar impaction followed Pell and Gregory's classification and Winter's classification standards (Winter, 1926; Pell and Gregory, 1933; Juodzbalys and Daugela, 2013).

Table 4 Type of lower third molars impaction

\begin{tabular}{lcc}
\multicolumn{1}{c}{ Type of impacted lower third molar } & Left side (\%) & Right side (\%) \\
Angulation of lower third molars & & \\
Mesioangular & $15(62.50)$ & $15(62.50)$ \\
Horizontal & $8(33.33)$ & $8(33.33)$ \\
Distoangular & $1(4.17)$ & $1(4.17)$ \\
Classification and positions of lower third molars & & \\
Class I Position A & $2(8.33)$ & $2(8.33)$ \\
Class I Position B & $3(12.50)$ & $3(12.50)$ \\
Class II Position A & $6(25.00)$ & $6(25.00)$ \\
Class II Position B & $9(37.50)$ & $9(37.50)$ \\
Class II Position C & $3(12.50)$ & $3(12.50)$ \\
Class III Position C & $1(4.17)$ & $1(4.17)$ \\
\hline
\end{tabular}

\section{pH of Mepivacaine}

Table 5 showed the mean $\mathrm{pH}$ of $2 \%$ mepivacaine with $1: 100,000$ epinephrine, $3 \%$ plain mepivacaine, and 3\% mepivacaine with 1:100,000 epinephrine, respectively. The $\mathrm{pH}$ of $2 \%$ mepivacaine with $1: 100,000$ epinephrine was significantly different than both $3 \%$ plain mepivacaine and 3\% mepivacaine with $1: 100,000$ epinephrine $(p<0.0001)$. However, the significant difference in the mean $\mathrm{pH}$ between the two groups of $3 \%$ mepivacaine could not be found $(p>0.05)$.
Table 6 showed EPT results before and after injection of either $2 \%$ mepivacaine with $1: 100,000$ epinephrine or 3\% mepivacaine with 1:100,000 epinephrine, of the canine and lower first molar on the same side of the surgical intervention. As stated in Table 6, after the administration of $2 \%$ mepivacaine with $1: 100,000$ epinephrine or $3 \%$ mepivacaine with $1: 100,000$ epinephrine, the post-injection EPT test showed no statistically significant differences with the EPT test before administering the local anaesthetic $(p>0.05)$. 
Table $5 \mathrm{pH}$ of each concentration of local anaesthetics used in this study

\begin{tabular}{lccc}
\multicolumn{1}{c}{ Drug } & $\boldsymbol{N}$ & Mean & SD \\
$\begin{array}{l}\text { 2\% mepivacaine with } \\
\text { 1:100,000 epinephrine }\end{array}$ & 10 & 3.89 & 0.15 \\
$\begin{array}{l}\text { 3\% mepivacaine plain } \\
\text { 3\% mepivacaine with }\end{array}$ & 10 & 5.89 & 0.05 \\
1:100,000 epinephrine & 10 & 5.88 & 0.02 \\
\hline
\end{tabular}

\section{Onset of Anaesthesia}

As presented in Table 6, the total volume of $2 \%$ mepivacaine with $1: 100,000$ epinephrine used was greater than $3 \%$ mepivacaine with 1:100,000 epinephrine, but without any statistically significant differences $(p>$ $0.05)$. The subjective, which are the signs of "tingling" of the lower lip (Elliott and van Hassel, 1977), and objective, which is the non-painful vital tooth (related to the EPT), onset of anaesthesia for both mepivacaine concentrations were recorded. There were no statistically significant differences between subjective onset and objective onset among both groups of mepivacaine $(p>0.05)$.

Table 6 Comparison of the measurements between 2\% mepivacaine with 1:100,000 epinephrine and 3\% mepivacaine with 1:100,000 epinephrine

\begin{tabular}{|c|c|c|c|}
\hline \multirow{2}{*}{ Measurement } & \multicolumn{2}{|c|}{ 1:100,000 epinephrine } & \multirow{2}{*}{$p$-value } \\
\hline & $2 \%$ mepivacaine & $3 \%$ mepivacaine & \\
\hline \multicolumn{4}{|l|}{ EPT before administration } \\
\hline Canine & $22.25 \pm 9.12$ & $21.63 \pm 10.22$ & 0.753 \\
\hline Lower first molar & $14.33 \pm 7.39$ & $16.00 \pm 9.34$ & 0.376 \\
\hline \multicolumn{4}{|l|}{ EPT after administration } \\
\hline Canine & $61.50 \pm 6.35$ & $61.50 \pm 6.33$ & 1.000 \\
\hline Lower first molar & $47.04 \pm 16.23$ & $46.46 \pm 18.57$ & 0.709 \\
\hline Total volume of local anaesthesia $(\mathrm{mL})$ & $3.15 \pm 0.59$ & $2.96 \pm 0.56$ & 0.096 \\
\hline \multicolumn{4}{|l|}{ Onset of anaesthetic action (min) } \\
\hline Subjective onset & $3.54 \pm 1.10$ & $3.54 \pm 0.83$ & 0.909 \\
\hline Objective onset & $10.46 \pm 2.57$ & $10.67 \pm 1.63$ & 0.737 \\
\hline Anaesthetic duration (min) & $205.88 \pm 35.36$ & $215.04 \pm 34.31$ & 0.184 \\
\hline Duration of postoperative analgesia (min) & $171.29 \pm 64.42$ & $171.92 \pm 60.83$ & 0.902 \\
\hline \multicolumn{4}{|l|}{ VAS score } \\
\hline Local anaesthesia injection & $14.08 \pm 8.67$ & $15.88 \pm 9.58$ & 0.129 \\
\hline Tooth sectioning & $6.92 \pm 10.11$ & $3.21 \pm 7.17$ & 0.113 \\
\hline
\end{tabular}

\section{Duration of Anaesthesia (Duration of Tingling and the Non-Painful Sense with EPT)}

While 3\% mepivacaine with 1:100,000 epinephrine has a longer period of anaesthesia in comparison with $2 \%$ mepivacaine with $1: 100,000$ epinephrine, there was also no statistically significant difference $(p>0.05)$. In addition, the mean duration of postoperative anaesthesia for $2 \%$ mepivacaine with 1:100,000 epinephrine and $3 \%$ mepivacaine with 1:100,000 epinephrine was not significantly different $(p>0.05)$.

\section{Pain Measurement}

Subjective pain is defined as the unpleasant feeling or experience that is caused by the possibility or the actual tissue damage 
(Giordano et al., 2010; Sirintawat et al., 2017), which is bone and soft tissue in the case of our study. The pain intensity evaluation that was recorded by the patients showed that the subjective pain scores had no statistically significant differences $(p>0.05)$. For tooth sectioning, the subjective pain score of $2 \%$ mepivacaine with $1: 100,000$ epinephrine group was slightly greater than the 3\% mepivacaine with $1: 100,000$ epinephrine group. Nevertheless, there was no statistically significant difference as well $(p>0.05)$.

\section{Complications in This Study}

There were no adverse effects or any abnormal incidence that was noticed or reported by patients from either concentration of the local anaesthetic during administration, surgery, or the postoperative period.

\section{Haemodynamic Measurements}

No hypertensive peaks were found from the data showing that the two concentrations of mepivacaine did not affect the systolic and diastolic blood pressure during the ILTMS (Fig. 2). As demonstrated in Fig. 3, the heart rate increased in the $2 \%$ mepivacaine with 1:100,000 epinephrine group during tissue incision and bone removal, yet no statistically significant differences were found between both groups of mepivacaine $(p>0.05)$. Moreover, there were also no statistically significant differences regarding the systolic and diastolic blood pressure at later stages of the surgical procedure $(p>0.05)$.

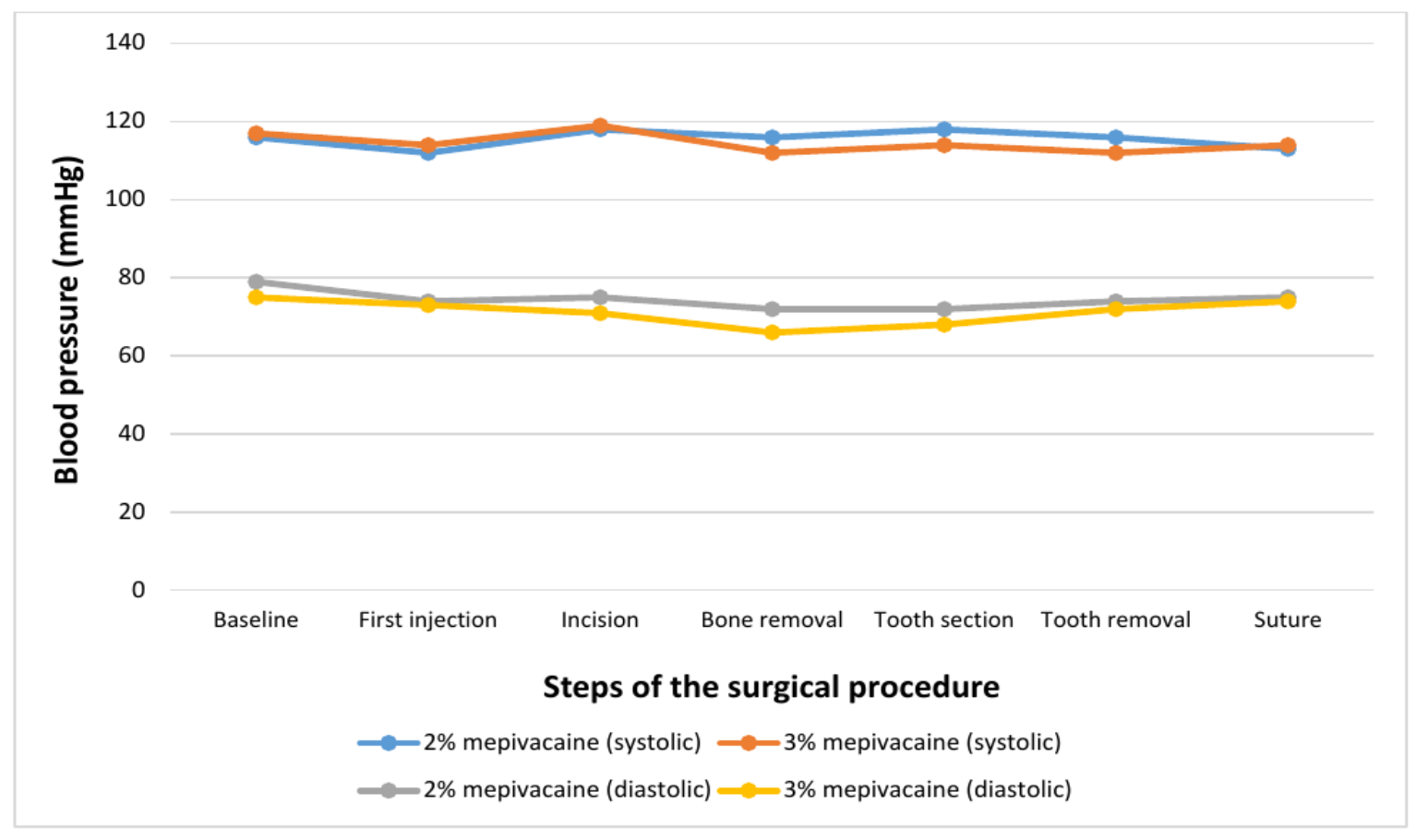

Fig. 2 Comparison of systolic and diastolic blood pressure (in $\mathrm{mmHg}$ ) between $2 \%$ and $3 \%$ mepivacaine groups during the steps of lower third molar surgery. 


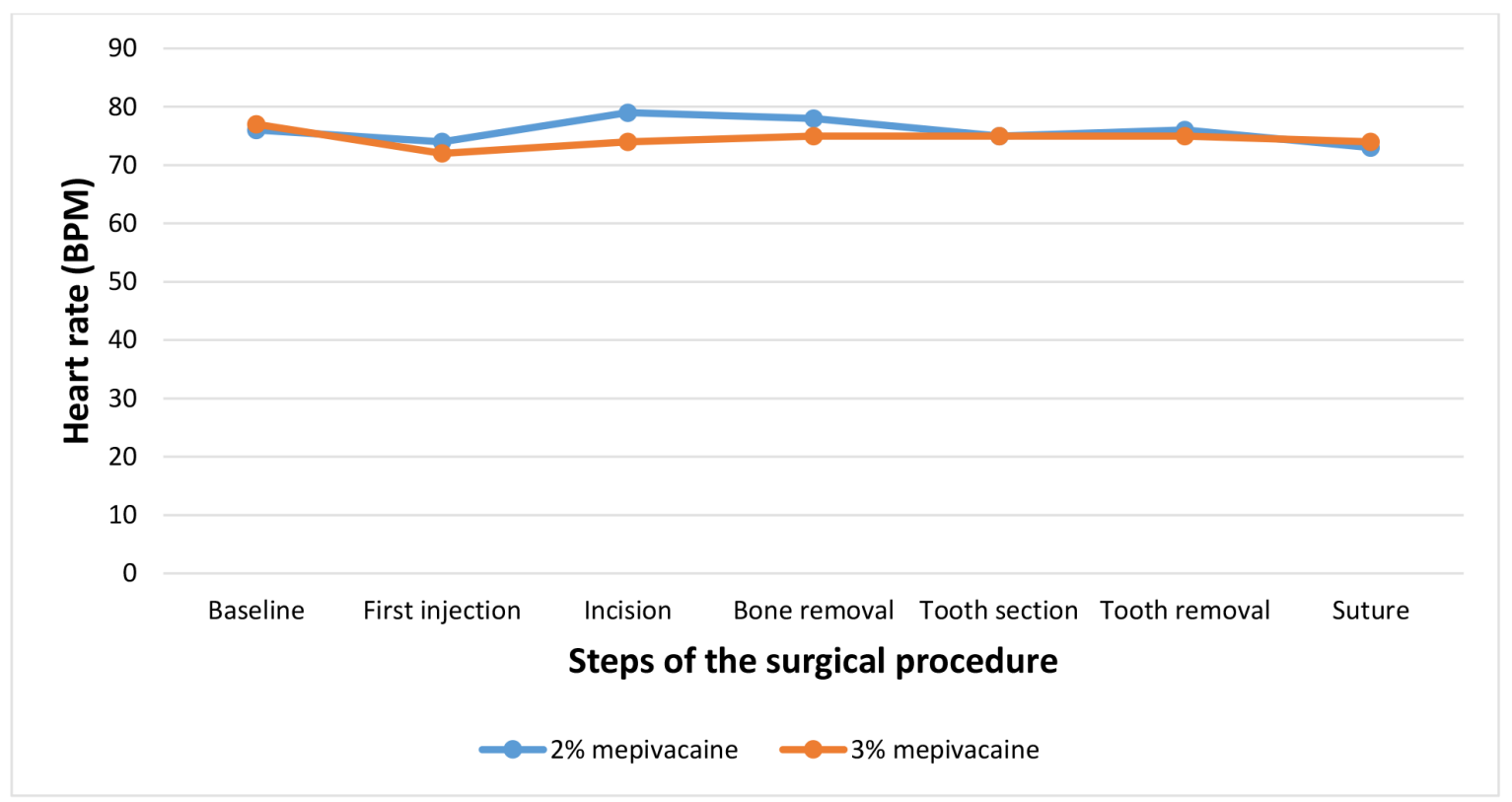

Fig. 3 Comparison of heart rate (in BPM) between 2\% and 3\% mepivacaine groups during the steps of lower third molar surgery.

\section{DISCUSSION}

To the best of the authors' knowledge, this study is considered novel as it is the first to evaluate and compare the clinical anaesthetic efficiency of $2 \%$ mepivacaine with 1:100,000 epinephrine against $3 \%$ mepivacaine with 1:100,000 epinephrine (different concentrations of local anaesthetic with the same concentration of vasoconstrictor) for the IANB when performing symmetrically positioned ILTMS. The study showed that there was no statistically significant difference in the anaesthetic efficiency between the two concentrations of mepivacaine. In other words, under the influence of the same concentration of vasoconstrictor; both concentrations of mepivacaine did not lead to any difference in ILTMS in terms of anaesthesia efficiency, complications, and intraoperative as well as postoperative pain. It is important to mention that the total volume used in each case for both concentrations of mepivacaine was not more than $3.6 \mathrm{~mL}$ when performing the operations. Supplemental local anaesthesia was not needed in both groups of mepivacaine. Thus, it seems possible to say that $2 \%$ mepivacaine with $1: 100,000$ epinephrine is a sufficient and effective anaesthetic for IANB for the ILTMS.

In this study, each first injection comprised of either $2 \%$ mepivacaine with 1:100,000 epinephrine or $3 \%$ mepivacaine with 1:100,000 epinephrine. Mild pain was reported by the patients during the administration of these two concentrations of mepivacaine. The mean VAS pain scores when using $2 \%$ mepivacaine with 1:100,000 epinephrine and 3\% mepivacaine with 1:100,000 epinephrine was in the mild pain range and there was no statistically significant difference.

From the $\mathrm{pH}$ records of $2 \%$ mepivacaine with 1:100,000 epinephrine, 3\% mepivacaine with 1:100,000 epinephrine, and 3\% plain mepivacaine, there is a significant difference in the $\mathrm{pH}$ of $2 \%$ mepivacaine, which was lower than both 3\% mepivacaine solutions. This significant difference in the $\mathrm{pH}$ of $2 \%$ mepivacaine, however, did not cause any noticeable difference in the VAS pain scores during local anaesthetic administration between all concentrations of mepivacaine 
as was assumed before recording the VAS scores. Reports only showed slightly less pain when using $2 \%$ mepivacaine with $1: 100,000$ epinephrine.

A previous study by McKay et al. (1987) asserted that the increase of local anaesthetic $\mathrm{pH}$ by adding sodium bicarbonate could reduce the pain of injection, which, however was not in consensus with our study, as it was found that $2 \%$ mepivacaine with 1:100,000 had a lower $\mathrm{pH}$ and caused slightly less pain. Additionally, the cause of pain seems to depend on many factors, rather than only the $\mathrm{pH}$.

Moreover, Wahl et al. (2006) assumed that there might be a relationship between the $\mathrm{pH}$ of the local anaesthetics and the degree of pain. They evaluated the pain perception after the administration of plain prilocaine, plain mepivacaine, and lidocaine with epinephrine and articaine with epinephrine for the IANB and maxillary palatal and buccal infiltration. They concluded that the injection of prilocaine was significantly less painful than mepivacaine, lidocaine, and articaine as it has more $\mathrm{pH}$. This also was not consistent with our study results. However, as mentioned earlier, no significant difference was found regarding the VAS scores in both groups.

In addition, Becker and Reed (2012) mentioned that anaesthetic potency depends on the concentrations of local anaesthetic agents, which typically range from $0.5 \%$ to $4 \%$. The results from our study found that the subjective pain of the patients while tooth sectioning, using $2 \%$ mepivacaine with $1: 100,000$ epinephrine is slightly more than when using 3\% mepivacaine with 1:100,000 epinephrine, yet, the difference between both groups were not statistically significant.

Furthermore, both different concentrations of mepivacaine had a similar onset of anaesthesia. As was assumed before, the onset of anaesthetic action may be related to the concentration of the local anaesthetic solution. In other words, the higher concentration can provoke a more rapid onset of anaesthesia, as it reaches the axons and bind to the receptor site at a faster rate. Therefore, the current study expected that $3 \%$ mepivacaine with $1: 100,000$ epinephrine may have a faster anaesthetic onset than $2 \%$ mepivacaine with $1: 100,000$ epinephrine due to the higher concentrations of local anaesthetic. Nonetheless, there was no significant difference in the onset of anaesthesia between both concentrations of mepivacaine.

Moreover, McLean et al. (1993) found no significant difference of the pulpal onset of anaesthesia between $4 \%$ prilocaine, 3\% mepivacaine and $2 \%$ lidocaine. Similarly, Vreeland et al. (1989) found that no difference of the onset of anaesthesia between $2 \%$ and $4 \%$ lidocaine in both lateral incisors and first molars extractions. The onset of anaesthesia of anaesthetic solution is determined by its pKa. Since, mepivacaine is used in both groups, the $\mathrm{pKa}$ values would be the same despite the fact that 3\% mepivacaine would have higher concentration of molecules per unit volume compared to the $2 \%$ mepivacaine (Malamed, 2012). It confirmed the result of this study, suggesting that the concentration of the local anaesthetic may not be a significant factor that affects the onset of anaesthesia.

In addition, this study showed that the duration of postoperative anaesthesia using both $2 \%$ mepivacaine with 1:100,000 epinephrine and 3\% mepivacaine with 1:100,000 epinephrine was similar, stating that an equal efficiency of postoperative duration of anaesthesia will be achieved using $2 \%$ or $3 \%$ mepivacaine as a local anaesthetic. Since duration of anaesthesia produced by a local anaesthetic solution is primarily determined by its protein binding capacity (Malamed, 2012), both doses of mepivacaine had similar duration of anaesthesia in this study. However, the slightly higher duration of anaesthesia in 3\% mepivacaine compared to $2 \%$ mepivacaine might be attributed to its greater concentration. 
There were no adverse events from the use of any of the concentrations of mepivacaine in this study. No abnormal findings or symptoms were noticed by the surgeon during the follow-up visits, and nothing was reported by the patients during the postoperative period. One patient had an incidence of paraesthesia after surgery. Therefore, the data related to this patient was excluded from this study as it was considered to be irrelevant to local anaesthetic factors. The paraesthesia of this patient was improved, and he recovered in a period of two months after the date of surgery.

The purpose of this study is to show that the IANB using $2 \%$ mepivacaine with $1: 100,000$ epinephrine and 3\% mepivacaine with $1: 100,000$ epinephrine was found to be not significantly different concerning the clinical anaesthetic efficiency in the ILTMS. As a result, the authors would like to emphasise that $2 \%$ mepivacaine with 1:100,000 epinephrine is sufficient and effective for IANB in the ILTMS. In addition, adding epinephrine to the plain 3\% mepivacaine did not make any significant effect on the heart rate or blood pressure, and did not cause adverse effects on a healthy adult patient. On the contrary, it might serve as a good factor to prolong the duration of local anaesthesia, as it is a vasoconstrictor. Therefore, upon adding the vasoconstrictor to the $3 \%$ plain mepivacaine without getting any harmful or side effects, the authors would like to suggest that $2 \%$ mepivacaine with $1: 100,000$ epinephrine is effective and safe, and it is recommended to use when there is a need for haemostasis and a longer duration of anaesthesia, or when the clinician notices that the case might be difficult and will consume a longer period of time to perform. In addition, 3\% plain mepivacaine does not show any potential benefit or advantage over the $2 \%$ mepivacaine with $1: 100,000$ epinephrine, and the use of $3 \%$ plain mepivacaine might not be of a great benefit, especially in points that were mentioned earlier, as adding the vasoconstrictor did not show any harmful effect on healthy adult patients.
One limitation that can be thought of in this study is that all patients were healthy and did not have any medical problems, any systemic disease, or any previous medical illness. This may give a sign that the judgement of the possibility of using only $2 \%$ mepivacaine with 1:100,000 epinephrine is sufficient for the ILMS is not entirely accurate. However, as mentioned before, there was no presence of any significant or noticeable adverse effect or negative outcome when epinephrine was added to the 3\% mepivacaine, which gives a good vision that $2 \%$ mepivacaine with 1:100,000 epinephrine is safe to use with patients. Further studies regarding this suggestion might be of high value in confirming this outcome.

The other limitation of this study might be the small sample size and high drop-out. Although, $10 \%$ more patients were recruited than the required sample, around $28 \%$ patients dropped out from the study. This might have affected the power of estimates. Further studies with optimal study sample is therefore recommended.

\section{CONCLUSION}

Nevertheless, there was no presence of any significant or noticeable adverse effect or negative outcome of both formulas. The judgement of the possibility of using only $2 \%$ mepivacaine with $1: 100,000$ epinephrine is sufficient for the ILMS, which gives a good vision that $2 \%$ mepivacaine with $1: 100,000$ epinephrine is safe to use with patients.

\section{ACKNOWLEDGEMENTS}

The authors would like to thank the staff, colleagues and dental assistants including co-workers in the Department of Oral and Maxillofacial Surgery, Faculty of Dentistry, Mahidol University. The authors also would like to thank Christian Estacio for editing and revising the language of this manuscript. This research study did not receive funding from any sponsors or scholarship. 


\section{REFERENCES}

Adeleye A, Sharp L, Rech MA (2020). Neurotoxicity secondary to local tetracaine use. Am f Emerg Med, 38(9): 1984. e1-1984.e3. https://doi.org/10.1016/j. ajem.2020.05.026

Arumugam S, Contino V, Kolli S (2020). Local Anesthetic Systemic Toxicity (LAST): A review and update. Curr Anesthesiol Rep, 10(2): 218-226. https://doi.org/10.1007/ s40140-020-00381-x

Becker DE, Reed KL (2012). Local anesthetics: Review of pharmacological considerations. Anesth Prog, 59(2): 90-101. https://doi. org/10.2344/0003-3006-59.2.90

Bortoluzzi M, Manfro R, Kafer G, Busetti L (2008). Comparative study of the efficacy of articaine and mepivacaine: A doubleblind, randomized, clinical trial. Internet $\mathcal{f}$ Dent Sci, 7(1): 1-7.

Colombini BL, Modena KC, Calvo AM, Sakai VT, Giglio FP, Dionísio TJ et al. (2006). Articaine and mepivacaine efficacy in postoperative analgesia for lower third molar removal: A double-blind, randomized, crossover study. Oral Surg Oral Med Oral Pathol Oral Radiol Endod, 102(2): 169-174. https://doi.org/10.1016/j. tripleo.2005.09.003

Elliott GD, van Hassel HJ (1977). Objective signs of inferior alveolar nerve anesthesia in exodontia. Oral Surg Oral Med Oral Pathol, 43(1): 38-40. https://doi.org/10.1016/0030$4220(77) 90347-4$

Hawkins JM, Moore PA (2002). Local anesthesia: Advances in agents and techniques. Dent Clin North Am, 46(4): 719-732. https://doi.org/10.1016/s00118532(02)00020-4

Giordano J, Abramson K, Boswell MV (2010). Pain assessment: Subjectivity, objectivity, and the use of neurotechnology. Pain Physician, 13(4): 305-315.
Giovannitti JA Jr, Rosenberg MB, Phero JC (2013). Pharmacology of local anesthetics used in oral surgery. Oral Maxillofac Surg Clin North Am, 25(3): 453-465. https://doi. org/10.1016/j.coms.2013.03.003

Juodzbalys G, Daugela P (2013). Mandibular third molar impaction: Review of literature and a proposal of a classification. F Oral Maxillofac Res, 4(2): e1. https://doi. org/10.5037/jomr.2013.4201

Katyal V (2010). The efficacy and safety of articaine versus lignocaine in dental treatments: A meta-analysis. $\mathcal{f}$ Dent, 38(4): 307-317. https://doi.org/10.1016/j. jdent.2009.12.003

Khalil H (2014). A basic review on the inferior alveolar nerve block techniques. Anesth Essays Res, 8(1): 3-8. https://doi. org/10.4103/0259-1162.128891

Malamed SF (2012). Handbook of Local Anesthesia, 6th edn. St. Louis: Elsevier Mosby.

McKay W, Morris R, Mushlin P (1987). Sodium bicarbonate attenuates pain on skin infiltration with lidocaine, with or without epinephrine. Anesth Analg, 66(6): 572-574.

McLean C, Reader A, Beck M, Meryers WJ (1993). An evaluation of $4 \%$ prilocaine and $3 \%$ mepivacaine compared with $2 \%$ lidocaine $(1: 100,000$ epinephrine $)$ for inferior alveolar nerve block. $\mathcal{F}$ Endod, 19(3): 146-150. https://doi.org/10.1016/ s0099-2399(06)80510-8

Moodley DS (2017). Local anaesthetics in dentistry - Part 3: Vasoconstrictors in local anaesthetics. S Afr Dent F, 72(4): 176-178.

Pell GJ, Gregory GT (1933). Impacted mandibular third molars: Classification and impacted mandibular third molars: Classification and modified technique for removal. Dent Dig, 39: 330-338. 
Santos CF, Modena KC, Giglio FP, Sakai VT, Calvo AM, Colombini BL et al. (2007). Epinephrine concentration (1:100,000 or $1: 200,000)$ does not affect the clinical efficacy of $4 \%$ articaine for lower third molar removal: A doubleblind, randomized, crossover study. $\mathcal{F}$ Oral Maxillofac Surg, 65(12): 2445-2452. https://doi.org/10.1016/j.joms.2007.04.020

Senes AM, Calvo AM, Colombini-Ishikiriama BL, Gonçalves PZ, Dionísio TJ, Sant'ana E et al. (2015). Efficacy and safety of $2 \%$ and $4 \%$ articaine for lower third molar surgery. f Dent Res, 94(9 Suppl): 166S-1673S. https://doi.org/10.1177/0022034515596313

Seto M, Matsuda M, Narihira K, Kikuta $\mathrm{T}$ (2016). Oral surgery under local anesthesia with dexmedetomidine sedation in a morbidly obese patient with aortic dissection. I Korean Assoc Oral Maxillofac Surg, 42(3): 162-165. https://doi. org/10.5125/jkaoms.2016.42.3.162

Sirintawat N, Sawang K, Chaiyasamut T, Wongsirichat N (2017). Pain measurement in oral and maxillofacial surgery. $\mathcal{F}$ Dent Anesth Pain Med, 17(4): 253-263. https:// doi.org/10.17245/jdapm.2017.17.4.253

Sisk AL (1992). Vasoconstrictors in local anesthesia for dentistry. Anesth Prog, 39(6): 187-193.
Son HW, Park SH, Cho HO, Shin YJ, Son JH (2016). Epinephrine-induced lactic acidosis in orthognathic surgery: A report of two cases. F Korean Assoc Oral Maxillofac Surg, 42(5): 295-300. https://doi.org/10.5125/ jkaoms.2016.42.5.295

Su N, Liu Y, Yang X, Shi Z, Huang Y (2014). Efficacy and safety of mepivacaine compared with lidocaine in local anaesthesia in dentistry: A meta-analysis of randomised controlled trials. Int Dent F, 64(2): 96-107. https://doi.org/10.1111/ idj. 12087

Vreeland DL, Reader A, Beck M, Meyers W, Weaver J (1989). An evaluation of volumes and concentrations of lidocaine in human inferior alveolar nerve block. If Endod, 15(1): 6-12. https://doi.org/10.1016/S00992399(89)80091-3

Wahl MJ, Schmitt MM, Overton DA (2006). Injection pain of prilocaine plain, mepivacaine plain, articaine with epinephrine, and lidocaine with epinephrine. Gen Dent, 54(3): 168-171.

Winter GB (1926). Impacted Third Molars. St Louis: American Medical Book Co., pp. 241-279.

Wolters U, Wolf T, Stützer H, Schröder $T$ (1996). ASA classification and perioperative variables as predictors of postoperative outcome. $\mathrm{Br} \mathcal{F}$ Anaesth, 77(2): 217-222. https://doi.org/10.1093/ bja/77.2.217 